\title{
Unintended Consequences of Internal Wall Insulation; Increased Risk of Mould Growth for Uninsulated Neighbours
}

\author{
Dr Matthew Brooke-Peat ${ }^{\mathrm{a}}$, Dr David Glew ${ }^{\mathrm{a} *}$ \\ a Leeds Sustainability Institute, Leeds Beckett University, Leeds, UK
}

\begin{abstract}
Internal Wall Insulation (IWI) retrofits reduce heat loss from homes, increase comfort and reduce fuel bills, however, they can result in unintended consequences. This paper uses thermal modelling to show that if only one side of a party wall is fitted with IWI, the surface temperature of the uninsulated side will reduce, and its risk of mould growth and surface condensation increases. This has potential implications for works under the Party Wall etc. Act 1996 that is applicable in England and Wales, and the room by room approaches to IWI retrofits. Peer-review under the responsibility of the organizing committee of the ICMB21.
\end{abstract}

Keywords: IWI; Retrofit; Mould; Party Wall, Surface Condenstion; Unintended Consequences; Thermal Modelling

\section{Introduction/Background}

The Energy Company Obligation (ECO) funds retrofits to improve the energy efficiency of homes whose occupants are in fuel poverty [1]. Approximately $10 \%$ of all households in the UK are in fuel poverty, this rises to $16 \%$ of households in uninsulated solid walled homes [2]. Since 2013, 2.8 million houses in the UK have been retrofitted through ECO, yet despite there being eight million solid walled homes in the UK, only 7\% of ECO measures have been solid wall insulation (SWI), and only a fraction of these, less than 7,000 homes, have had internal wall insulation (IWI) [3]. This disproportionally low uptake of IWI may be due to its relatively higher costs compared to other retrofits [4], as well as concerns over the risk of unintended consequences [5-8].

\section{Aim and rationale}

This paper presents the results of field trials and thermal modelling to evaluate one such risk; the potential for increasing the risk of mould growth in solid walls homes around party walls when the neighboring house has been retrofitted with IWI. The addition of IWI reduces the temperature of the external wall behind the insultation, since it limits the heat transfer from the room to the wall. The external wall of the insulated dwelling will now be colder than its uninsulated neighbour, meaning heat will be transferred from the adjoining external wall and party wall. This withdrawal of heat, resulting from the IWI, may therefore not only reduce the wall temperatures directly behind the insulation, it may also reduce wall surface temperatures in the adjacent dwelling around the party wall junction. Lower external and party wall internal surface temperatures could increase the risk of mould growth and surface condensation in neighbouring properties; this has legal ramifications for IWI retrofits, as well as health and energy implications.

\section{Method}

Thermal bridging to party wall junctions with external walls in a case study brick-built terrace property, constructed circa 1900 in Leeds were modelled before and after an IWI retrofit, using the Physibel TRISCO version $12.0 \mathrm{w}$ software to ascertain the linear thermal transmittance ( $\Psi$-value $)$ and temperature factor $\left(f_{\text {Rsi }}\right)$. Thermal modelling conventions do not cover thermally asymmetric party wall junctions [9]. Therefore, a procedure had to be devised that utilised independent boundary conditions to each side of the party wall enabling heat flow $(\mathrm{Q})$ and surface temperature $\left(\mathrm{T}_{\mathrm{si}}\right)$ to be individually ascertained for each dwelling [6]. A critical temperature factor $\left(f_{\text {CRsi }}\right)$ of 0.750 was applied to avoid mould growth in UK dwellings as identified in IP 1/06 [10]. The case study featured high levels of IWI that were being installed in social housing projects.

\section{Results}

A $f_{\text {Rsi }}$ of 0.718 was calculated for both sides of the party wall junction before renovation and this is below the $f_{\text {CRsi }}$ of 0.750 , which is deemed to present a potential risk of mould growth in dwellings. It is noteworthy, that the risk of mould growth was already present in the adjoining dwelling prior to retrofit. Table 1 shows the results for the range of IWI upgrade scenarios modelled. These include no return, $600 \mathrm{~mm}$ return or the full return of $50 \mathrm{~mm}$ PIR insulation along the party wall.

\footnotetext{
* Corresponding author. +44 (0) 1138127623 d.w.glew@leedsbeckett.ac.uk
} 
Table 1. Results for Thermal Bridging Calculations

\begin{tabular}{|l|c|c|c|c|}
\hline \multicolumn{1}{|c|}{ Junction: } & $\boldsymbol{\Psi}_{\mathbf{1}}(\mathrm{W} / \mathrm{m} \cdot \mathrm{K}):$ & $\boldsymbol{\Psi}_{\mathbf{2}}(\mathrm{W} / \mathrm{m} \cdot \mathrm{K}):$ & $\boldsymbol{f}_{\text {Rsi1 }}:$ & $\boldsymbol{f}_{\text {Rsi2 }}:$ \\
\hline Uninsulated Base Case & 0.232 & 0.232 & 0.718 & 0.718 \\
\hline 100mm IWI No return & 0.135 & 0.320 & 0.877 & 0.682 \\
\hline 100mm IWI 600mm return & 0.033 & 0.404 & 0.960 & 0.672 \\
\hline 100mm IWI Full Return & 0.029 & 0.409 & 0.960 & 0.672 \\
\hline 150mm IWI No Return & 0.106 & 0.339 & 0.904 & 0.677 \\
\hline 150mm IWI 600mm return & 0.026 & 0.410 & 0.970 & 0.670 \\
\hline 150mm IWI Full Return & 0.023 & 0.414 & 0.970 & 0.671 \\
\hline
\end{tabular}

Note: Values with subscript one (e.g. $\left.\Psi_{1}\right)$ apply to upgraded dwelling, subscript two (e.g. $\left.\Psi_{2}\right)$ apply to the adjoining dwelling.

Where an IWI retrofit only occurs to one side of the party wall, the risk of mould growth is removed from the surface of the corner to that dwelling, however, the $f_{\text {Rsi }}$ reduces in the un-renovated dwelling, which increases the risk of mould growth. The $f_{\text {Rsi }}$ further reduces in the un-renovated dwelling when thicker IWI is applied to the external wall in the renovated dwelling. Adding a $600 \mathrm{~mm}$ return exacerbates the risk in the uninsulated neighbouring property at the party wall junction. A negligible difference to this risk was found between $600 \mathrm{~mm}$ return and full return scenarios.

\section{Discussion}

The thermal bridging calculations indicate that asymmetric reduction of heat flow into party walls could reduce surface temperatures of walls to a neighbouring dwelling. This unintended consequence potentially increases risk of mould growth for neighbouring uninsulated dwellings and may increase their heat losses. This corresponds with observations made by others for different constructions [11-13]. Mould growth is not inevitable, but risks are increased dependent upon moisture levels and surface characteristics in adjacent rooms. These findings have potential implications for works under the Party Wall etc. Act 1996 as well as the potential for health and energy penalties for neighbours. The findings also have implications for a partial, room by room, approach to IWI retrofits, which can be favored by social landlords and householders preferring to delay insulating kitchens and bathrooms until they are due for wear and tear renewal. Finally, surface condensation could be more likely in adjacent uninsulated rooms after a partial IWI retrofit is undertaken. However, room use, and occupant behavior determine moisture load, which substantially influences the likelihood of condensation.

\section{Conclusions}

Findings from this paper challenge common practices in the UK for installing IWI. The thermal models suggest that IWI retrofits can increase risk of mould growth and surface condensation on the uninsulated side of party and partition walls. Although the risk of mould was present prior to retrofit, these findings have practical and potential legal ramifications for the UK retrofit industry and may need addressing to encourage widespread uptake of IWI.

\section{References}

[1] HM Government. (2017). Statutory Instrument 2017 No. 490 The Electricity and Gas (Energy Company Obligation) (Amendment) Order 2017. London.

[2] Department for Business Energy \& Industrial Strategy. (2020). Annual Fuel Poverty Statistics in England, 2020 (2018 data). London.

[3] Department for Business Energy \& Industrial Strategy. (2020). Headline HEE Release Tables, December 2020. London.

[4] Palmer J, Livingstone M, and Adams A. (2017). What Does It Cost to Retrofit Homes; Updating the Cost Assumptions for BEIS's Energy Efficiency Modelling. Department of Business, Energy and Industrial Strategy. London.

[5] Glew, D., Smith, M., Miles-Shenton, D., and Gorse, C. (2017). Assessing the Quality of Retrofits in Solid Wall Dwellings. International Journal of Building Pathology and Adaptation. 35. 501-518.

[6] Gorse, C., Glew, D., Johnston, D., Fylan, F., Miles-Shenton, D., Brooke-Peat, M., Farmer, D., Stafford, A., Parker, J., Fletcher, M., and Thomas, F. (2017). Core Cities Green Deal Monitoring Project. Department of Business, Energy \& Industrial Strategy. London.

[7] King, C., and Weeks, C. (2016) Designing Out Unintended Consequences When Applying Solid Wall Insulation, IHS BRE Press. Watford.

[8] BRE. (2016). Solid Wall Heat Losses and the Potential for Energy Saving. Consequences for Consideration to Maximise SWI benefits: A Route-map for Change. Building Research Establishment. Watford.

[9] Ward, T., Hannah, G. and Sanders, C. (2016) Conventions for Calculating Linear Thermal Transmittance and Temperature Factors. BR 497. 2nd ed. HIS. St Albans.

[10]Ward, T. (2006) Assessing the Effects of Thermal Bridging at Junctions and Around Openings. IP 1/06. Building Research Establishment. Watford.

[11]Little, J., and Arregi, B. (2011). Thermal Bridging: Understanding its Critical Role in Energy Efficiency. Construct Ireland. 5.

[12]Weeks, C., Ward, T., and King, C. (2013). Reducing Thermal Bridging at Junctions when Designing and Installing Solid Wall Insulation, FB 61. IHS BRE Press. Watford.

[13] National Standards Authority of Ireland. (2014). Code of Practice for the Energy Efficient Retrofit of Dwellings. Standard Recommendation S.R.54:2014. Dublin. 